

Cite this: Phys. Chem. Chem. Phys., 2015, 17, 11898

Received 18th February 2015, Accepted 10th April 2015

DOI: $10.1039 / c 5 c p 01035 g$

www.rsc.org/pccp

\section{A THz/FTIR fingerprint of the solvated proton: evidence for Eigen structure and Zundel dynamics}

\author{
Dominique Decka, Gerhard Schwaab* and Martina Havenith
}

\begin{abstract}
In continuation of earlier work on $\mathrm{La}\left(\right.$ III), $\mathrm{Ni}(\mathrm{I})$ and $\mathrm{Mn}\left(\right.$ (I) halides, we present low frequency $\left(30-400 \mathrm{~cm}^{-1}\right.$ ) spectra of solvated $\mathrm{HCl}$ and $\mathrm{HBr}$ as a function of solute concentration. This frequency range provides direct access to water network modes and changes induced by solvated solutes. We were able to dissect the spectra into components associated to solvated ions and ion pairs using a chemical equilibrium model in combination with principal component analysis. While the $\mathrm{Cl}^{-}$rattling mode at $190 \mathrm{~cm}^{-1}$ is found to be unchanged, the $\mathrm{Br}^{-}$resonance around $90 \mathrm{~cm}^{-1}$ is decreased in intensity below the detection threshold when replacing the divalent or trivalent metal ions by a proton. The solvated proton shows two resonances: a solvation water mode around $140 \mathrm{~cm}^{-1}$ and a high frequency resonance at $325 \mathrm{~cm}^{-1}$ that we assign to the rattling motion of an Eigen structure $\mathrm{H}_{3} \mathrm{O}^{+}$in its solvation cage. This assignment is corroborated by isotopic substitution measurements which show a redshift of the high frequency peak when $\mathrm{HCl} / \mathrm{H}_{2} \mathrm{O}$ is replaced by $\mathrm{DCl} / \mathrm{D}_{2} \mathrm{O}$. The linewidth of the $\mathrm{H}_{3} \mathrm{O}^{+}$rattling mode corresponds to a relaxation time of the oscillatory process of $\tau \approx 60 \mathrm{fs}$, considerably faster than the relaxation time of $\tau \approx 160 \mathrm{fs}$ for $\mathrm{Cl}^{-}$. In addition, we find a broad background that we attribute to fast non-oscillatory motions of a proton in a Zundel-like complex. Our results are in agreement with an Eigen-Zundel-Eigen (EZE) model of proton transport. Upon ion pairing the broad background is strongly reduced indicating a reduction of fast proton transfer processes. The $\mathrm{Cl}^{-}$resonance blueshifts by $20 \mathrm{~cm}^{-1}$ which indicates a transition from free ions to a solvent shared ion pair. Surprisingly, the center frequency of the Eigen complex does not change upon ion pairing. This can be rationalized in terms of an unchanged local solvation structure.
\end{abstract}

\section{Introduction}

The microscopic structure and dynamics of the solvated proton are essential to understand a plethora of chemical and biochemical processes ranging from acid reactions to enzymatic catalyis. ${ }^{1}$ Several recent reviews summarize the large computational and experimental efforts to resolve this topic. ${ }^{2-7}$ Nevertheless, there is still a controversy on the size and structure of the solvated proton complex and the dynamical processes that lead to the exceptionally high equivalent conductivity of protons.

The latter effect was first rationalized in 1806 by C. J. T. de Grotthuss picturing a 'simple' hopping mechanism of (positively charged) hydrogen along a water chain, the so-called Grotthuss mechanism. ${ }^{2,8}$ Based on a multitude of experimental data, this picture was renewed by M. Eigen and others who found that the proton is permanently hydrated (primary hydration) and better described as $\mathrm{H}_{3} \mathrm{O}^{+}$. This Eigen cation is strongly interacting with its first solvation shell (secondary hydration) forming $\mathrm{H}_{9} \mathrm{O}_{4}{ }^{+}$, the Eigen complex. ${ }^{1}$ Later on, G. Zundel and coworkers found a

Department of Physical Chemistry II, Ruhr-University Bochum, Germany.

E-mail: gerhard.schwaab@rub.de; Fax: +49 (0)234 321 4183;

Tel: +49 (0)2343224256 continuum absorption in their IR-spectra of acids which they explained by introduction of $\mathrm{H}_{5} \mathrm{O}_{2}{ }^{+9,10}$ This so called Zundel cation was thought as part of a proton transport mechanism involving proton tunneling. ${ }^{11-13}$ However, pioneering ab initio studies by Tuckerman et al. ${ }^{14,15}$ showed that the solvated proton fluctuates between the Eigen and Zundel forms and that proton transport does not require a tunneling mechanism since the energy barrier vanishes with decreasing $\mathrm{O}-\mathrm{O}$ distance.

The discussion whether the Eigen, the Zundel or even other cationic forms are predominant is still ongoing. . $^{3,6,16-19}$ Part of the controversy is owing to the fact that most gas phase measurements and simulations focus on protonated water clusters neglecting the effects of the counter anion and ion pairing. ${ }^{19-21}$ This makes a comparison to measurements of concentrated acidic solutions difficult. ${ }^{22-24}$ Another challenge is the fast dynamics of the hydrogen bond network and the unknown mixing ratio of Eigen and Zundel complexes in a proton rich environment which complicates the data interpretation of standard structural methods like neutron scattering and infrared fingerprinting measurements. $6,17,25,26$

Nowadays, a multitude of simulations of the isolated proton yield a picture where the Eigen and Zundel forms are merely limiting cases or just part of a highly dynamic system involving 
the proton and its solvation environment..$^{2-5,7,27,28}$ In some cases, ultrafast conversion between both structures was postulated. ${ }^{14,29}$ Recently, a rather complex picture of proton transport along a 'proton wire' spanning several hydrogen bonds was postulated by Hassanali et al. in a first principles study. ${ }^{19}$ Simulations of aqueous acidic solutions are less abundant. ${ }^{23,30,31,32}$ While some of these investigations predict contact or solvent shared ion pairing between oppositely charged ions, ${ }^{30,31}$ others find a tendency of metastable contact ion pairs of hydrated excess protons. $^{32}$

Experimental studies of the solvated proton have been carried out along two directions. Gas phase infrared predissociation spectroscopic measurements of protonated water clusters $^{20,21,33,34}$ show spectra that depend heavily on the water cluster size indicating a strong size dependence of the local cage structure surrounding the solvated proton. Similar experiments on Zundel-type protonated complexes ${ }^{35}$ demonstrated that the observed center frequencies depend sensitively on the local solvation environment. Other studies focus on medium to high concentration aqueous acidic solutions mainly using $\mathrm{HCl}$ and $\mathrm{HBr}$ as simple model systems. Early work of Triolo and Narten in 1975 based on X-ray diffraction (XRD) and neutron diffraction with isotopic substitution (NDIS) describes the structure of an aqueous $\mathrm{HCl}$ solution as random tetrahedral network of oxygen atoms giving no indication if the Eigen or Zundel form prevails. $^{22}$ A more recent NDIS study by Botti et al. ${ }^{17,36}$ could reproduce the observed data equally well in a Monte Carlo analysis of the data when using either $\mathrm{H}^{+}, \mathrm{H}_{3} \mathrm{O}^{+}$, or $\mathrm{H}_{5} \mathrm{O}_{2}^{+}$as basic structure for the solvated proton. Photoelectron spectra ${ }^{18}$ of hydrochloric acid $(\mathrm{HCl})$ yielded no evidence for the $\mathrm{H}_{5} \mathrm{O}_{2}{ }^{+}$ structure of the proton. In contrast NMR and ATR-FTIR spectra of $\mathrm{HCl}(\mathrm{aq})$ show indications that both the Eigen and the Zundel complex are present in solution, with the Eigen form being the most abundant proton complex in agreement with theoretical results. ${ }^{23,25,26,37}$ At higher concentration (6-16 M), more recent $\mathrm{X}$-ray absorption fine structure (XAFS) measurements of aqueous $\mathrm{HCl}$ solutions yield Zundel-like ion pairs of $\mathrm{Cl}^{-}$and hydronium with a proton in the center and a $\mathrm{Cl}^{-}-\mathrm{H}^{+}$distance comparable to the Zundel cation. ${ }^{38}$ This is in agreement with a density functional theory based study which postulated the presence of solvent separated ion pairs for the dilute solution (2.7 M) and contact ion pairs for more concentrated solutions $(5.3 \mathrm{M}) .^{31}$ Based on concentration dependent infrared spectroscopic studies Stoyanov et al. ${ }^{6,39}$ concluded that the proton is solvated by six water and that its predominant structure in acidic solution is $\mathrm{H}_{13} \mathrm{O}_{6}{ }^{+}$including a Zundel-like moiety at the center with a particularly large O-O distance of $2.57 \AA$ A. Chen et al. performed $\mathrm{X}$-ray Raman and small angle X-ray scattering experiments on aqueous $\mathrm{HCl}$ and $\mathrm{NaOH}$ solutions and deduced the presence of locally strengthened hydrogen bonds around the proton ${ }^{40}$ as it was theoretically predicted by Markovitch and Agmon. ${ }^{41}$ Time resolved femtosecond pump-probe spectroscopy has also been used on acidic solutions ${ }^{24,42}$ and yielded very short proton relaxation times in the range 120-200 fs and a fast interconversion between the Eigen and Zundel forms. Tielrooij et al. ${ }^{43}$ compared terahertz time-domain spectra (THz-TDS) of acidic solutions to those of simple electrolytes and postulated Eigen complex structures and an extended water complex as part of a proton transport mechanism.

So far, precise absorption measurements in the frequency range $30-400 \mathrm{~cm}^{-1}$ are missing. To fill this gap, in the present study, we use concentration dependent THz/FTIR absorption spectroscopy to characterize $\mathrm{HCl}(\mathrm{aq})$. This technique is a powerful tool to investigate the hydration dynamics of solute molecules. Previous studies included proteins ${ }^{44}$ as well as zwitterions (e.g. glycine ${ }^{45}$ ) and ionic salts. ${ }^{46-49}$ For electrolyte solutions, we were able to separate solvated ion and ion pair spectra and to dissect the solvated ion spectrum into anion, cation and hydration water contributions. ${ }^{49}$ Here, we aim to apply the same method to obtain information on the solvation environment of the solvated proton and its ion pair complex.

\section{Material and methods}

Hydrochloric and hydrobromic acid solutions in the concentration range $0.05 \mathrm{M}$ to $3.2 \mathrm{M}$ were prepared using $12 \mathrm{M}$ stock solution (Sigma-Aldrich) by using HPLC grade ultra pure water. $\mathrm{DCl}$ in $\mathrm{D}_{2} \mathrm{O}$ solutions were prepared from $35 \%$ (weight) solutions of DCl (Sigma Aldrich) in $\mathrm{D}_{2} \mathrm{O}$ (Deutero). Apparent molar volumes of $\mathrm{HCl}$ and $\mathrm{HBr}$ were taken from literature, ${ }^{50,51}$ those of $\mathrm{DCl}$ from density measurements employing an Anton Paar DMA 58 density meter at $20 \pm 0.2{ }^{\circ} \mathrm{C}$.

Broadband FIR Fourier Transform absorption spectroscopic measurements were carried out using a Bruker Vertex 80 V FTIR spectrometer with a mylar multilayer beamsplitter in combination with a liquid helium cooled Si bolometer (Infrared Laboratories) as detector and a mercury arc lamp as radiation source. For an extended description of the technique refer to Schmidt et al. ${ }^{46}$ The electrolyte solutions were measured in the concentration ranges $0.05-2.5 \mathrm{M}, 0.4-3.2 \mathrm{M}$, and 0.6-2.5 $\mathrm{M}$ for $\mathrm{HCl}, \mathrm{HBr}$, and $\mathrm{DCl}$, respectively. As sample holder served a commercial Bruker liquid cell with CVD grown diamond windows (500 $\pm 100 \mu \mathrm{m}$ thickness; Diamond Materials, GmbH). This guaranteed maximum transparency over a broad frequency range (30-400 $\left.\mathrm{cm}^{-1}\right)$. The liquid layer thickness was maintained using $25 \pm 5 \mu \mathrm{m}$ thick Kapton spacers. The exact spacing size was determined by recording the etalon fringes of the empty cell in a Fourier Transform spectrometer. We kept the liquid cell under continuous nitrogen gas purging and temperature controlled conditions $\left(20 \pm 0.2^{\circ}\right)$ in a closed sample compartment which was separated by polyethylene flaps from the rest of the evacuated spectrometer chamber. Each spectrum was recorded with $2 \mathrm{~cm}^{-1}$ resolution and averaged over 128 scans.

The resulting total absorption coefficient of an electrolyte solution is given by:

$$
\alpha_{\text {solution }}(\tilde{\nu})=-\frac{1}{d} \log \left(\frac{I_{\text {solution }}(\tilde{\nu})}{I_{\text {bulk }}(\tilde{\nu})}\right)+\alpha_{\text {bulk }}(\tilde{\nu})
$$

with $d$ being the measured layer thickness, $\alpha_{\text {bulk }}$ the absorption coefficient of the bulk water reference (see Sharma et al., Appendix ${ }^{49}$ ) and $I_{\text {bulk }}$ and $I_{\text {solution }}$ being the transmitted intensities of the reference and sample, respectively. The $\mathrm{D}_{2} \mathrm{O}$ reference spectrum 
for the temperature of $20{ }^{\circ} \mathrm{C}$ was obtained from precise measurements of $\mathrm{D}_{2} \mathrm{O}$ with two different spacer thicknesses.

We deduced an effective ionic absorption $\alpha_{\text {ion }}^{\text {eff }}$ of the solvated ions according to

$$
\alpha_{\text {ion }}^{\text {eff }}=\alpha_{\text {solution }}-\frac{c_{\mathrm{w}}}{c_{\mathrm{w}}^{0}} \alpha_{\text {bulk }}(\tilde{\nu})
$$

with $c_{\mathrm{w}}$ being concentrations of water in the solution as obtained from literature data on the apparent molar volume of $\mathrm{HCl}^{50}$ and $\mathrm{HBr}^{51}$ or from density measurements. $c_{\mathrm{w}}^{0}$ is the water concentration in bulk water at the same temperature. $\alpha_{\text {ion }}^{\text {eff }}$ contains contributions from the ions and ion-associates as well as any change in the water absorption induced by the solvated ions compared to bulk water. ${ }^{48}$ For an ideal bi-component (cation(aq) + anion(aq)) electrolyte solution with negligible ion association $\alpha_{\text {eff }}^{\text {ion }}$ is strictly proportional to the salt concentration. Any nonlinear changes will therefore become apparent when calculating the molar effective ionic extinction $\left(\varepsilon_{\text {ion }}^{\text {eff }}=\frac{\alpha_{\text {ion }}^{\text {eff }}}{c_{\mathrm{s}}}\right)$ that is obtained by normalizing the effective ionic absorption to the molar salt concentration $c_{\mathrm{s}}$. For the ideal electrolyte solution $\varepsilon_{\text {ion }}^{\text {eff }}$ is expected to be independent of solute concentration.

\section{Experimental results}

Using our FIR/THz Fourier transform spectrometer, we have measured the concentration dependent absorption of hydrochloric acid and hydrobromic acid in aqueous solution with bulk water as reference in the concentration range 0.04-2.5 M and 1.1-4.4 M, respectively. General trends are visible in Fig. 1 where we display averages of several measurements at the same concentration covering the concentration ranges $0.4-2.5 \mathrm{M}$ for $\mathrm{HCl}$ and 1.1-4.4 $\mathrm{M}$ for $\mathrm{HBr}$. The absorption of both acidic solutions is increased over the full frequency range $\left(30-400 \mathrm{~cm}^{-1}\right)$ compared to bulk water absorption.

The deduced effective ionic extinctions (see insets in Fig. 1) have contributions of three absorption bands in the case of $\mathrm{HCl}$ and two for $\mathrm{HBr}$. For $\mathrm{HCl}$, the resonance around $180 \mathrm{~cm}^{-1}$ is attributed to $\mathrm{C} \mathrm{Cl}^{-}$rattling mode which has been observed before in measurements of $\mathrm{Cl}^{-}$containing salts. ${ }^{46-49}$ Furthermore we observe resonances for both, $\mathrm{HCl}$ and $\mathrm{HBr}$, at $\approx 130 \mathrm{~cm}^{-1}$ and $340 \mathrm{~cm}^{-1}$.

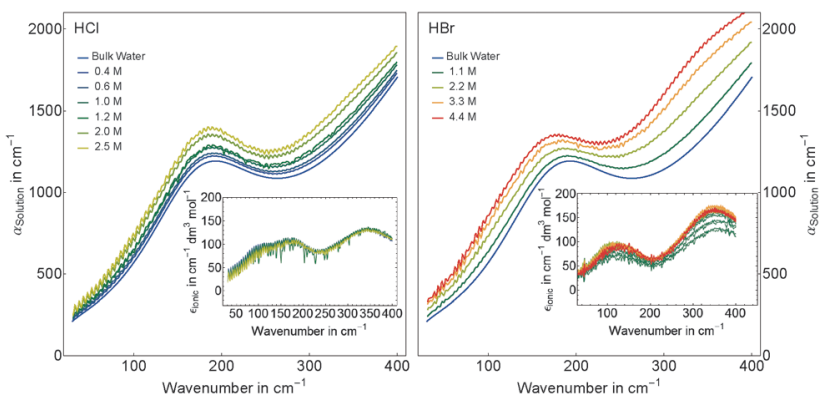

Fig. 1 Concentration dependent THz/FIR absorption of aqueous $\mathrm{HCl}$ (left) and $\mathrm{HBr}$ (right) solutions. Each data point was obtained as the average of several measurements. The insets show the ionic extinction. In both panels a certain color represents identical concentrations.
We propose that these originate either from hydration water modes or an eigen mode of the solvated proton complex.

\subsection{Spectrum dissection and discussion}

3.1.1 Separation of ionic and ion pair contributions. The dissection of the concentration dependent spectra for aqueous $\mathrm{HCl}$ and $\mathrm{HBr}$ solutions closely follows the procedure described in detail in Sharma et $a l^{49}$ As a first step, we performed a principal component analysis (PCA) to identify the major spectral components that are required to describe our full dataset. The significant first three principal components for $\mathrm{HCl}$ (left) and $\mathrm{HBr}$ (right) are displayed in Fig. 2. The concentration dependence of the corresponding scores is shown in Fig. 3. The first and third principal components describe solute concentration related changes in the overall data. The second principal component shows no systematic dependency on the solute concentration. It reflects residual water vapor absorption in the spectrometer beam path that is due to the inclusion of many low concentration measurements. For $\mathrm{HCl}(\mathrm{HBr})$, the first three principal components account for $90 \%$ (97\%) of the variance of a total of 192 (30) datasets.

As shown in Sharma et al. ${ }^{49}$ the concentration dependency of the scores of the solute related principal components can be
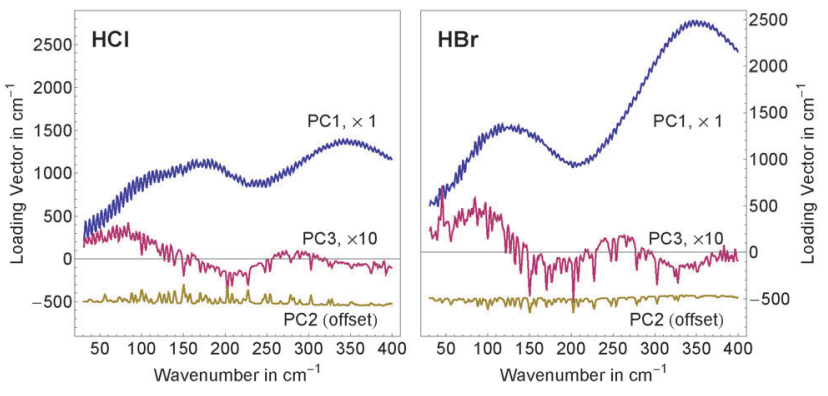

Fig. 2 Results of the principal component analysis: shown are the main principal components for aqueous $\mathrm{HCl}$ (left) and $\mathrm{HBr}$ (right) solutions. The first (blue) and third (red) principal components describe the spectral features attributed to the solvated solutes and ion pair formation. The second principal component (yellow) summarizes residual water vapor absorption in the beam path. For better comparability, an offset of $-500 \mathrm{~cm}^{-1}$ and a scaling factor of ten were applied to the second and third principal components, respectively.
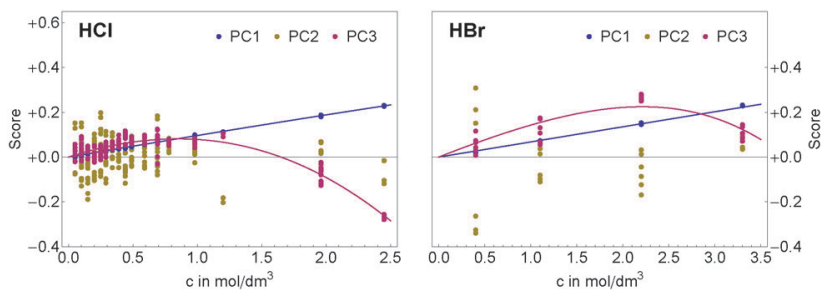

Fig. 3 Concentration dependency of the scores of the first three principal components for aqueous $\mathrm{HCl}$ (left) and $\mathrm{HBr}$ (right) solutions. The first principal component (blue) shows mostly linear behavior, while the nonlinearity of the third (red) principal components is indicative of ion pair formation. The second principal component (yellow) describes residual water vapor absorption in the beam path and is independent of the solute concentration. 
directly related to a simplified ion pair model where $\alpha_{\text {ion }}^{\text {eff }}(\tilde{\nu})$ is described as

$$
\alpha_{\text {ion }}^{\text {eff }}(\tilde{\nu})=c_{\mathrm{s}} \varepsilon_{\text {single }}^{\text {eff }}(\tilde{\nu})+c_{\text {pair }}\left(c_{\mathrm{s}}, K_{\text {pair }}\right) \varepsilon_{\text {diff }}^{\text {eff }}(\tilde{\nu}) .
$$

$\varepsilon_{\text {single }}^{\text {eff }}(\tilde{\nu})=\varepsilon_{\text {cation }}+\varepsilon_{\text {anion }}-n_{\text {hydration }} \varepsilon_{\text {bulk }}$ describes the effective extinction of solvated anion and cation (including their hydration cage). The negative term in $\varepsilon_{\text {single }}^{\text {eff }}$ accounts for the effective number $n_{\text {hydration }}$ of hydration water molecules that show a spectrum different from bulk water.

$$
\varepsilon_{\text {diff }}^{\operatorname{eff}}(\tilde{\nu})=\varepsilon_{\text {pair }}^{\operatorname{eff}}(\tilde{\nu})-\varepsilon_{\text {single }}^{\text {eff }}(\tilde{\nu})
$$

corresponds to the difference between the ion pair extinction and the anion and cation extinctions. ${ }^{48}$ The ion pair concentration $c_{\text {pair }}\left(c_{\mathrm{s}}, K_{\text {pair }}\right)$ of the equilibrium reaction

$$
\mathrm{H}^{+}(\mathrm{aq})+\mathrm{X}^{-}(\mathrm{aq}) \stackrel{K_{\mathrm{pair}}}{\rightleftharpoons}(\mathrm{H}(\mathrm{aq}) \mathrm{X})
$$

is determined by the association constant $K_{\text {pair }}$ and the mean activity coefficients $\gamma_{\text {anion }}, \gamma_{\text {cation, }}$, and $\gamma_{\text {pair }}$ of anion, cation and ion pair, respectively:

$$
c_{\text {pair }}\left(c_{\mathrm{s}}\right)=K_{\text {pair }} c_{\text {anion }} c_{\text {cation }} \frac{\gamma_{\text {anion }} \gamma_{\text {cation }}}{\gamma_{\text {pair }}} .
$$

As described in detail in Sharma et $a l^{49}$ we have simplified eqn (6) by assuming that the chemical structures of solvated ion-pair and solvated cation are similar yielding $\gamma_{\text {pair }} \approx \gamma_{\text {cation. }}$. The mean activity coefficients for $\mathrm{HCl}$ and $\mathrm{HBr}$ were taken from experimental data by Pitzer and Mayorga. ${ }^{52}$ In Fig. 3, we display the concentration dependence of the scores. The scores to principal components PC1 and PC3 of each acid were globally fitted to functions of the form

$$
s_{i}\left(c_{\mathrm{s}}\right)=c_{\mathrm{s}} a_{i}^{\text {lin }}+c_{\text {pair }}\left(c_{\mathrm{s}}, K_{\text {pair }}\right) a_{i}^{\text {nlin }}, i=\{1,3\}
$$

with linear and non-linear fitting parameters $a_{i}^{\text {lin }}$ and $a_{i}^{\text {nlin }}$, respectively, using the same association constant $K_{\text {pair }}$ for $s_{1}$ and $s_{3}$. As can be seen, the scores are reproduced when adjusting the parameters $K_{\text {pair }}(\mathrm{HCl})=0.13(4)$ and $K_{\text {pair }}(\mathrm{HBr})=$ $0.034(1)$ to fit the experimental data.

Ion pair formation has a nonlinear salt concentration dependence ( $\propto c_{\text {anion }} c_{\text {cation, }}$, see eqn (6)). In contrast, in the dilute limit, the contribution $c_{\mathrm{s}} \varepsilon_{\text {single }}^{\text {eff }}$ to the effective ionic absorption scales linearly with $c_{\mathrm{s}}$ (see eqn (3)). Therefore, the effective ion extinction $\varepsilon_{\text {single }}^{\text {eff }}$ can be directly related to the slopes of the score functions $s_{i}\left(c_{\mathrm{s}}\right)$ evaluated at $c_{\mathrm{s}}=0$ :

$$
\varepsilon_{\text {single }}^{\text {eff }}=\left.\sum_{i=1,3} \frac{\mathrm{d} s_{i}}{\mathrm{~d} c_{\mathrm{s}}}\right|_{c_{\mathrm{s}}=0} V_{i}=\sum_{i=1,3} a_{i}^{\text {lin }} V_{i}
$$

where $V_{i}$ denotes the $i$ th principal component and $\frac{\mathrm{d} s_{i}}{\mathrm{~d} c_{\mathrm{s}}}$ the derivative of the score function belonging to principal component $i$ with respect to the salt concentration. The right hand equality follows directly from a comparison of eqn (3) and (7). Following the same reasoning, $\varepsilon_{\text {diff }}^{\text {eff }}$ is related to the nonlinear fit parameters in eqn (7):

$$
\varepsilon_{\mathrm{diff}}^{\mathrm{eff}}=\sum_{i=1,3} a_{i}^{\mathrm{nlin}} V_{i}
$$
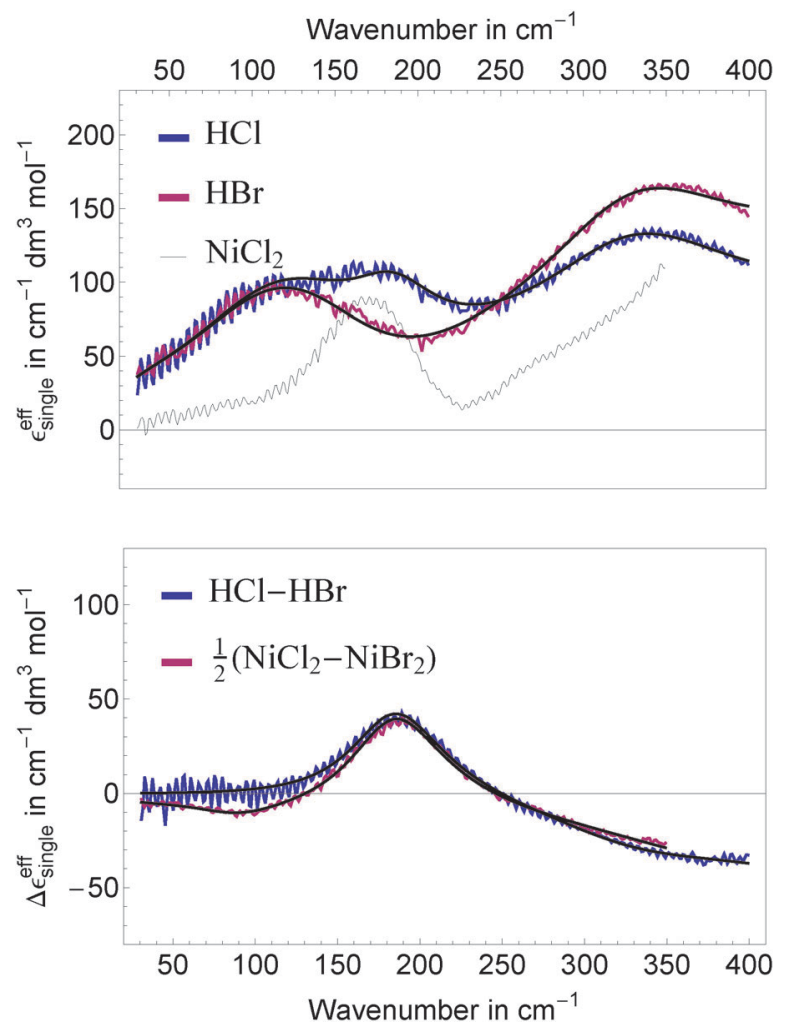

Fig. 4 Top: effective ionic extinctions $\varepsilon_{\text {single }}^{\text {eff }}$ for $\mathrm{HCl}$ (blue), $\mathrm{HBr}$ (red) and $\mathrm{NiCl}_{2}$ (thin black line). Bottom: difference $\Delta \varepsilon_{\text {single }}^{\text {eff }}$ between the ionic extinctions for $(\mathrm{HCl}, \mathrm{DCl})$ and $\left(\mathrm{NiCl}_{2}, \mathrm{NiBr}_{2}\right)$. The difference for the $\mathrm{Ni}^{2+}$ halides has been scaled by 0.5 to account for the larger number of anions. The thick black lines show the result of a global fit for the $\mathrm{H}^{+}$as well as the $\mathrm{Ni}^{2+}$ and $\mathrm{Mn}^{2+}$ halides and their differences.

In Fig. 4, top panel, we display the resulting effective ionic extinction spectra of $\mathrm{HCl}$ and $\mathrm{HBr}$ as well as $\varepsilon_{\text {single }}^{\text {eff }} \mathrm{NiCl}_{2}$ for comparison. For both, $\mathrm{HCl}$ and $\mathrm{HBr}$, two main resonances centered around 100 and $350 \mathrm{~cm}^{-1}$ are visible. In case of $\mathrm{HCl}$ an additional, weaker resonance is found at $180 \mathrm{~cm}^{-1}$ that is more prominent when plotting the difference $\mathrm{HCl}-\mathrm{HBr}$ as displayed in the bottom panel. A similar spectral feature is found when plotting the difference $\Delta \varepsilon_{\text {single }}^{\text {eff }}$ for $1 / 2\left(\mathrm{NiCl}_{2}-\mathrm{NiBr}_{2}\right)$. This resonance is attributed to the rattling mode of $\mathrm{Cl}^{-}$as observed before. ${ }^{47,49}$ Center frequency and linewidth of the mode are the same within our experimental uncertainty. This indicates that both, hydration cage structure, i.e. force constant and reduced mass, which determine the center frequency, and the relaxation dynamics determining the linewidth of this rattling mode remain unchanged when replacing $\mathrm{Ni}^{2+}$ by the solvated proton as counter cation. In contrast, at low frequencies $\left(\tilde{\nu} \leq 120 \mathrm{~cm}^{-1}\right)$ the bromide rattling resonance at $90 \mathrm{~cm}^{-1}$ is found to be decreased below the detection threshold for aqueous HBr solutions.

3.1.2 Dissection of ionic spectra. To get more insight into the physical processes determining the spectra of acidic solutions, we extended the fitting procedure described in Sharma et al. ${ }^{49}$ to include the effective ionic extinctions of $\mathrm{HCl}(\mathrm{aq})$ and $\mathrm{HBr}(\mathrm{aq})$ and their differences with the Ni(II) and Mn(II) halide solutions. 
We aimed for minimizing the number of additional fit parameters (Ockham's razor) while keeping a physically self-consistent model description. The extinction spectra were modeled by a combination of scaled low frequency and high frequency bulk water modes describing the low and high frequency parts of the measured spectra and modified damped harmonic oscillator functions as described by us previously for distinct ionic and hydration water modes. ${ }^{49}$ The global fit included a total of six extinction spectra ( $\left.\mathrm{HCl}, \mathrm{HBr}, \mathrm{NiCl}_{2}, \mathrm{NiBr}_{2}, \mathrm{MnCl}_{2}, \mathrm{MnBr}_{2}\right)$ and nine spectral differences ( $\mathrm{HCl}-\mathrm{HBr}, \mathrm{NiCl}_{2}-\mathrm{NiBr}_{2}, \mathrm{MnCl}_{2}-\mathrm{MnBr}_{2}$, HCl-0.5 $\mathrm{NiCl}_{2}, \mathrm{HCl}-0.5 \mathrm{MnCl}_{2}, \mathrm{HBr}-0.5 \mathrm{NiBr}_{2}, \mathrm{HBr}-0.5 \mathrm{MnBr}_{2}$, $\mathrm{NiCl}_{2}-\mathrm{MnCl}_{2}, \mathrm{NiBr}_{2}-\mathrm{MnBr}_{2}$ ). To properly describe the extended dataset, 35 parameters had to be fitted compared to 27 parameters for the $\mathrm{Ni}$ (II) and $\mathrm{Mn}$ (II) halide data alone. The eight additional parameters describe the rattling mode of the solvated proton and the effect of $\mathrm{HCl}$ and $\mathrm{HBr}$ on the hydration water.

The most important fit results are summarized in Table 1. The best fit was obtained, when we kept the unperturbed center frequency of the low frequency water modes identical for salt and acidic solutions, but varied the linewidth. The center frequencies of the anion and cation resonances are well reproducible with an estimated uncertainty of $\pm 1 \mathrm{~cm}^{-1}$. For $\mathrm{HCl}$, the resonance assigned to $\mathrm{a} \mathrm{Cl}^{-}$rattling mode is centered at $187 \mathrm{~cm}^{-1}$ and shows a linewidth of $226 \mathrm{~cm}^{-1}$. We note in passing, that the anionic amplitudes in Table 1 are values per mole of anion compared to Sharma et $a l^{49}$ (per mole of salt) leading to a scaling factor of 0.5 for a direct comparison of the corresponding values.

3.1.3 Solvated proton resonances. Both, $\mathrm{HCl}$ and $\mathrm{HBr}$ acidic extinction spectra show two damped harmonic oscillator modes with unperturbed center frequencies of $141 \mathrm{~cm}^{-1}$ and $338 \mathrm{~cm}^{-1}$ and a linewidth of $w \approx 560 \mathrm{~cm}^{-1}$ (see Fig. 4).
The corresponding short decay time ${ }^{49}$ of 60 fs compares favorably to the intermediate time constant of 54 fs found by Markovitch et al. ${ }^{53}$ (Fig. 4) using several computational quantum chemical and classical methods. A similar time constant was also found using a more rigorous method by Chandra et $a l .{ }^{54}$ and Tuckerman et al. ${ }^{55}$

We assign the high frequency mode at $338 \mathrm{~cm}^{-1}$ to a blueshifted hindered translational mode of a (possibly distorted) Eigen species $\mathrm{H}_{3} \mathrm{O}^{+}$in the surrounding water network. This is in agreement with Fig. 5a shown by Lapid et al. ${ }^{29}$ where an oscillatory motion with an approximate time constant of $100 \mathrm{fs}$ $\left(\approx 330 \mathrm{~cm}^{-1}\right)$ is found between the excess proton in $\mathrm{a}_{3} \mathrm{H}^{+}$ moiety and its nearest neighbor oxygen prior and after a proton transfer event. Such a mode around $350 \mathrm{~cm}^{-1}$ is also prominent in the vibrational density of states published by Kim et al., ${ }^{37}$ (Fig. 7) based on multistate empirical valence bond simulations. The blue shift can be explained by a stronger confinement of the Eigen species compared to bulk water. Indeed, a shortened $\mathrm{O}-\mathrm{H}$ distance in protonated solutions compared to bulk water was found by neutron diffraction and simulation studies. ${ }^{17,32,36}$ To corroborate our assignment we performed concentration dependent measurements of $\mathrm{DCl}$ in $\mathrm{D}_{2} \mathrm{O}$ and applied the same data analysis as for $\mathrm{HCl}$ and $\mathrm{HBr}$ in $\mathrm{H}_{2} \mathrm{O}$ (see Fig. 5). In agreement with our prediction, the center frequency of the resonance at $338 \mathrm{~cm}^{-1}$ is found to be redshifted by $\approx 15-20 \mathrm{~cm}^{-1}$ upon deuteration.

The low frequency mode centered at $\tilde{\nu}_{\mathrm{d}} \approx 110 \mathrm{~cm}^{-1}$ resembles the resonance found in $\mathrm{Ni}$ (II) and $\mathrm{Mn}$ (II) halide solutions assigned to solvation water. ${ }^{49}$ Indeed, the best fit for a given number of fit parameters is obtained, when we assume a model, where the unperturbed center frequency $\nu_{0}$ of this water mode is identical for transition metal cations, halides and the solvated proton,

Table 1 Center frequency $\tilde{\nu}_{d}$, corrected center frequency $\tilde{\nu}_{0}$, amplitude $a$, and linewidth $w$ for acidic $\mathrm{HCl}$ and $\mathrm{HBr}$ as well as $\mathrm{MBr}_{2}$ and $\mathrm{MCl} 2(\mathrm{M}=\mathrm{Ni}, \mathrm{Mn})$ solutions (see Fig. 4) obtained from a global fit including the $\mathrm{Ni}$ and $\mathrm{Mn}$ halide data published by us before. ${ }^{49}$ We have used damped harmonic oscillator line shapes for the ionic and water resonances and scaled bulk water relaxational ( $n_{\mathrm{LF}}$ ) and librational ( $n_{\mathrm{HF}}$ ) modes as models for the low frequency and high frequency components. In addition, a contribution $n_{\text {hydration }}$ was added accounting for the hydration water. The numbers in brackets correspond to $2 \sigma$ statistical errors. Text labels indicate that the same fit parameter was used for a description of line parameters for different resonances

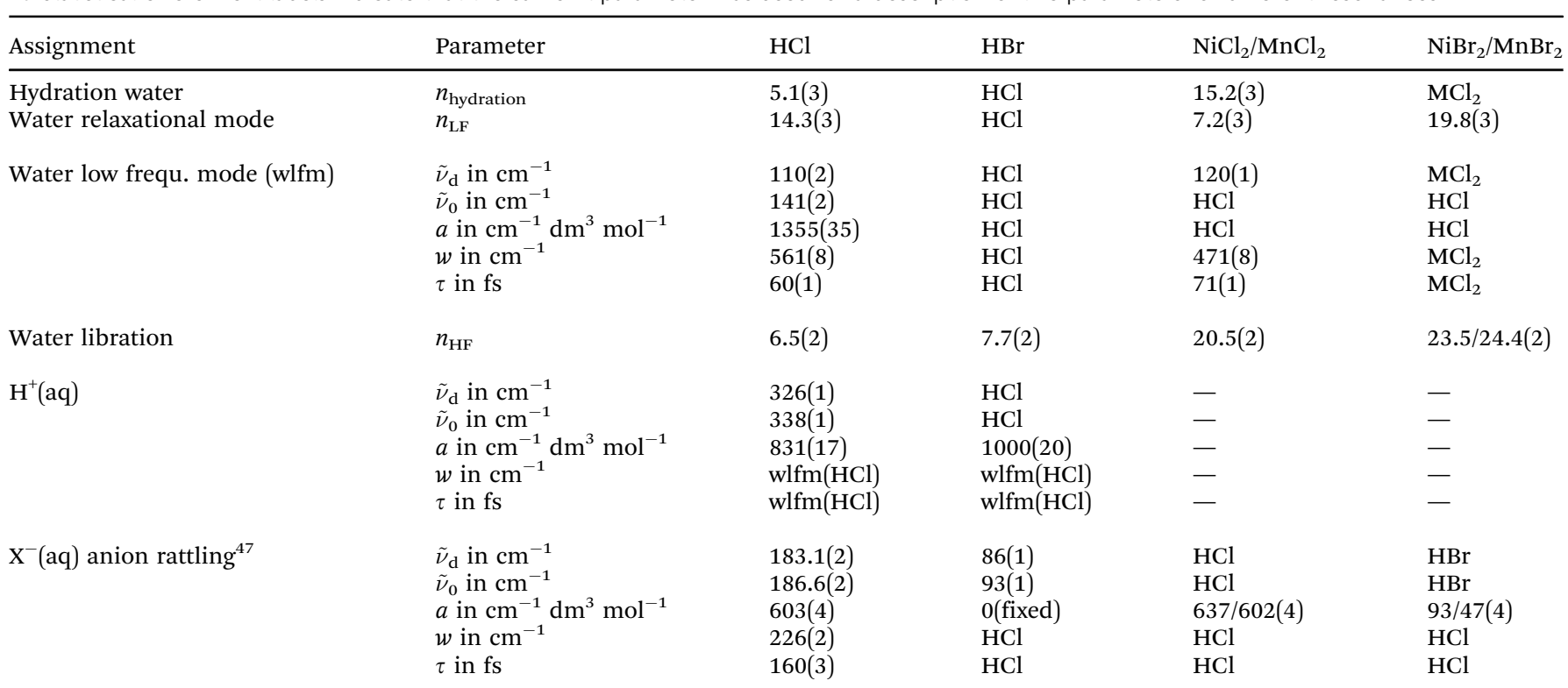




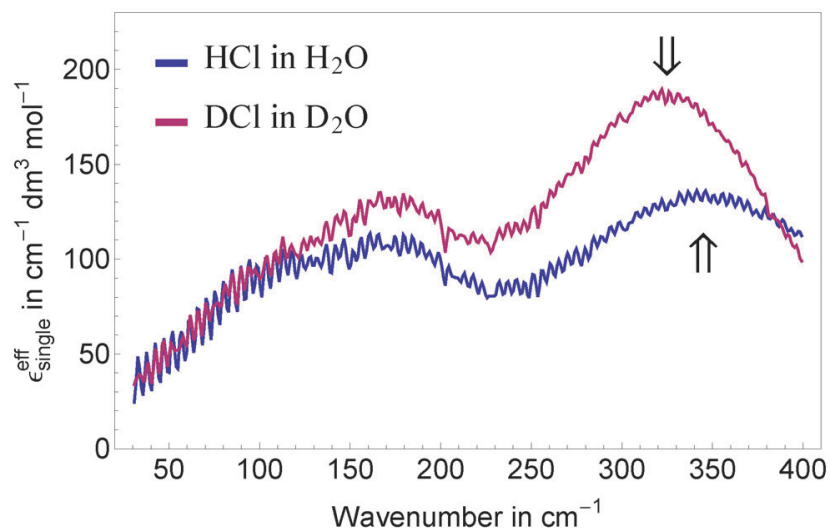

Fig. 5 Comparison of the effective ionic extinctions of $\mathrm{HCl}$ in $\mathrm{H}_{2} \mathrm{O}$ and $\mathrm{DCl}$ in $\mathrm{D}_{2} \mathrm{O}$ showing a redshift of the high frequency resonance around $340 \mathrm{~cm}^{-1}$ when replacing $\mathrm{H}$ by the heavier isotope.

however with an increased linewidth $\left(560 \mathrm{~cm}^{-1}\right.$ compared to $470 \mathrm{~cm}^{-1}$ ) for the acidic case. We take this as evidence for a locally enhanced mobility of the hydration network around a $\mathrm{H}_{3} \mathrm{O}^{+}$ moiety compared to bulk water. This higher mobility accounts also for disappearance of the $\mathrm{Br}^{-}$rattling mode in $\mathrm{HBr}$ around $90 \mathrm{~cm}^{-1}$ : according to Sharma et al., ${ }^{49}$ given a linewidth of $560 \mathrm{~cm}^{-1}$ any oscillation below $\nu_{\mathrm{d}} \approx 90 \mathrm{~cm}^{-1}$ is overdamped showing relaxational rather than oscillatory behavior.

The linewidths of modes assigned to different ions give information on the spatial extent of mobility enhancement: in the case of the solvated proton the linewidths of the low frequency hydration water mode and of the hydronium rattling mode are identical within our measurement uncertainty. This is in contrast to our previous results for $\mathrm{Ni}(\mathrm{II})$ and $\mathrm{Mn}$ (II) halides $^{49}$ where both, the rattling motions of weakly solvated anions as well as the eigen modes of the supermolecular complex consisting of a strongly hydrated cation and its first solvation shell have a smaller linewidth than the low frequency water mode.

Since linewidths are intimately related to the spectral distribution of thermal bath states interacting with the embedded oscillator, we propose that the narrower lines observed for solvated $\mathrm{Cl}^{-}, \mathrm{Br}^{-}, \mathrm{Ni}^{2+}$, and $\mathrm{Mn}^{2+}$ resonances reflect the reduced rotational mobility of water in their first hydration shell. ${ }^{56}$ The larger widths observed for the low frequency water mode of these simple electrolytes provide evidence for a coupling to rotationally more flexible water, probably in the second solvation layer. We speculate that the identical linewidths found for the $\mathrm{H}_{3} \mathrm{O}^{+}$rattling mode and the hydration water mode can be explained by rapid charge delocalization in the $\mathrm{H}_{9} \mathrm{O}_{4}{ }^{+}$Eigen complex as already considered by Eigen himself ${ }^{1}$ and later predicted in theoretical investigations. ${ }^{5,53}$ Such a 'special pair dance' would blur the boundary between first and second solvation shell water.

3.1.4 Hydration water. The combined influence of anions and cations on the surrounding hydration water is described by three fit parameters: $-n_{\text {hydration }} \varepsilon_{\text {bulk }}(\tilde{\nu})$ describes the correction required to account for the effective number of water molecules influenced by the solute, the dynamic hydration shell. Similarly, $n_{\mathrm{LF}}$, and $n_{\mathrm{HF}}$ are scaling factors describing the solute effects on the low frequency relaxational part $\varepsilon_{\mathrm{LF}}(\tilde{\nu})$ and the high frequency librational part $\varepsilon_{\mathrm{HF}}(\tilde{\nu})$ of water, respectively. ${ }^{49}$ The water extinction spectrum $\varepsilon_{\text {bulk }}(\tilde{\nu})=\varepsilon_{\mathrm{LF}}(\tilde{\nu})+\varepsilon_{\text {trans }}(\tilde{\nu})+\varepsilon_{\mathrm{HF}}(\tilde{\nu})$ is the sum of its hindered translation band $\varepsilon_{\text {trans }}(\tilde{\nu})$ centered at around $200 \mathrm{~cm}^{-1}$ and its relaxational low frequency (LF) and librational high frequency (HF) bands. Therefore, in our fit model $n_{\text {hydration }}$ mainly reflects the influence of the ions on the $200 \mathrm{~cm}^{-1}$ translational band which is dominated by localized nearest neighbor hindered translational motions. ${ }^{57}$ As for the $\mathrm{Ni}(\mathrm{II})$ and $\mathrm{Mn}$ (II) halides we are not able to separate a priori the anionic and cationic influences on the three fit parameters.

3.1.4.1 $n_{\text {hydration. }}$ From our fit results we obtain a dynamical solvation shell size $n_{\text {hydration }} \approx 5$ for $\mathrm{HCl}$ and $\mathrm{HBr}$. This solvation shell size can be either due to the proton or due to the anion or a combination of both. Stoyanov et al. ${ }^{6,39}$ claim $\mathrm{H}_{13} \mathrm{O}_{6}{ }^{+}$as unique structure for the solvated proton yielding a cationic solvation shell size of six water in agreement with our data. However, an assignment of $n_{\text {hydration }}$ solely to the proton leads to $n_{\text {hydration }}\left(\mathrm{X}^{-}\right)=0$ and $n_{\text {hydration }}\left(\mathrm{M}^{2+}\right)=15(\mathrm{M}=\mathrm{Ni}, \mathrm{Mn})$. This is surprisingly large, considering that $n_{\text {hydration }}$ describes the localized nearest neighbor hindered translation and that the replacement of a water molecule in the local network by a much heavier anion or cation should affect mainly the hindered translational modes within the solute's first solvation layer.

Therefore, we propose that the dynamic solvation shell size $n_{\text {hydration }} \approx 5$ found by us is dominated by the anion. This yields $n_{\text {hydration }}\left(\mathrm{X}^{-}\right) \approx 5$ and $n_{\text {hydration }}\left(\mathrm{H}^{+}\right) \approx 0(\mathrm{X}=\mathrm{Cl}, \mathrm{Br})$ which is in agreement with solvation shell sizes of $n=4-5$ and $n=4-6$ that have been determined for $\mathrm{Cl}^{-}$and for $\mathrm{Br}^{-}$, respectively, using neutron and X-ray scattering techniques (Ohtaki and Radnai $^{58}$ and references therein) and with predictions in recent theoretical studies. ${ }^{30,31}$ Other computational studies predict even larger average anionic solvation shell sizes in the range $n=7-8 .^{59-61}$ In addition, such an assignment yields dynamic solvation shell sizes of 5-6 for $\mathrm{Ni}^{2+}$ and $\mathrm{Mn}^{2+}$ (see Table 1) which is consistent with the octahedral coordination ${ }^{58}$ expected for these cations.

3.1.4.2 $n_{H F}$. If we would attribute $n_{\mathrm{HF}}(\mathrm{HX}), \mathrm{X}=\mathrm{Cl}, \mathrm{Br}$, to the Eigen species, we obtain an asymmetric situation with $n_{\mathrm{HF}}\left(\mathrm{X}^{-}\right)=0$ and $n_{\mathrm{HF}}\left(\mathrm{M}^{2+}\right)=20-25$. This is not consistent with our previous results in transition metal halides, ${ }^{49}$ which showed that $\mathrm{Br}^{-}$ influences the librational band more than $\mathrm{Cl}^{-}$. In contrast, if we choose $n_{\mathrm{HF}}\left(\mathrm{H}_{3} \mathrm{O}^{+}\right)=0$ we obtain $n_{\mathrm{HF}}\left(\mathrm{X}^{-}\right)=7-8$ for the anions and $n_{\mathrm{HF}}\left(\mathrm{M}^{2+}\right)=8-9$ for the cations $(\mathrm{M}=\mathrm{Ni}, \mathrm{Mn})$. In this picture, metal cations and halide anions disturb the librational motion of the first shell water molecules in a similar way, while the local perturbation of the hydrogen bond network around the solvated proton is small.

3.1.4.3 $n_{L F}$. This mode is found to be strongly enhanced for $\mathrm{HCl}$ and $\mathrm{HBr}$ acidic solutions compared to the solvated transition metal halides where only a small increase of the low frequency extinction was found (see Fig. 5 in Sharma et al. ${ }^{49}$ ). 
We propose that this enhancement results from fast nonoscillatory proton motion within a Zundel type solvated proton structure yielding a broad background contribution to the measured extinction spectrum in the THz/FIR frequency range. Such fast movements with correlation times of a few $(<10)$ femtoseconds have been predicted theoretically. $5,29,53,62$

The broadband increase in extinction is also in agreement with THz-TDS measurements performed by Tielrooij et al. ${ }^{43}$ in the frequency range up to $1.2 \mathrm{THz}\left(40 \mathrm{~cm}^{-1}\right)$ who found an increased imaginary part $\varepsilon^{\prime \prime}$ of the dielectric response for $\mathrm{HCl}$ compared to e.g. NaCl. They attributed this experimental result exclusively to changes in the relaxation process $S_{1}(\tau \approx 8 \mathrm{ps})$ of water molecules surrounding the ions thereby neglecting the influence of the higher frequency $S_{2}(\tau \approx 0.25 \mathrm{ps})^{63}$ process. However, we want to point out that processes with short relaxation times become more prominent with increasing frequency.

There is a proportionality $\alpha \propto \varepsilon^{\prime \prime} \omega / n$ between the dielectric absorption coefficient $\alpha$ and $\varepsilon^{\prime \prime}$ with $\omega=2 \pi \nu$ as angular frequency and $n$ as index of refraction of the solution. Here, $\nu$ is the excitation frequency of the source driving the oscillation. In case of a relaxational Debye mode with strength $S$ and relaxation time $\tau$ we find:

$$
\begin{aligned}
& \varepsilon^{\prime \prime}(\omega) \propto \frac{S \omega \tau}{1+\omega^{2} \tau^{2}} \stackrel{\omega \tau \gg 1}{\longrightarrow} \frac{S}{\omega \tau} \\
& \alpha(\omega) \propto \frac{S \omega^{2} \tau}{1+\omega^{2} \tau^{2}} \stackrel{\omega \tau \gg 1}{\longrightarrow} \frac{S}{\tau} .
\end{aligned}
$$

For water at room temperature $S_{1} \approx 80, \tau_{1} \approx 8 \mathrm{ps}, S_{2} \approx 6$, and $\tau_{2} \approx 0.25 \mathrm{ps}$. This implies that both processes contribute equally to the imaginary part of the dielectric spectrum at frequencies around $\nu=1 \mathrm{THz}(\omega=6.3 \mathrm{THz})$. Therefore, the $S_{2}$ process must not be neglected. ${ }^{63}$ A description of spectral changes at $\mathrm{THz}$ frequencies in terms of process $S_{1}$ only will therefore result in a misinterpretation of the data.

\subsection{Ion pairing}

We used eqn (4), (8), and (9) to calculate $\varepsilon_{\text {pair }}^{\text {eff }}(\tilde{\nu})$. Fig. 6 shows the ion pair spectra for $\operatorname{HCl}(\mathrm{aq})$ and $\operatorname{HBr}(\mathrm{aq})$ retrieved from our concentration dependent measurements and the corresponding linear extinction coefficients $\varepsilon_{\text {single }}^{\text {eff }}$ of the separated ions. To avoid confusion with un-dissociated $\mathrm{HCl}$, we will use $\left(\mathrm{H}^{+}-\mathrm{X}^{-}\right), \mathrm{X}=\mathrm{Cl}, \mathrm{Br}$, to denote an ion pair in solution. For $\mathrm{HCl}$ we observe a reduction in the broad background over the full spectral range and a blue-shift of the $\mathrm{Cl}^{-}$rattling peak to a center frequency of $\approx 200 \mathrm{~cm}^{-1}$. This is especially prominent in the difference spectrum $\varepsilon_{\text {pair }}^{\text {eff }}\left(\mathrm{H}^{+}-\mathrm{Cl}^{-}\right)-\varepsilon_{\text {pair }}^{\text {eff }}\left(\mathrm{H}^{+}-\mathrm{Br}^{-}\right)$as displayed in the inset of Fig. 6. For $\mathrm{HBr}$, part of the broad background is still visible at frequencies below $50 \mathrm{~cm}^{-1}$. The resonance at $330 \mathrm{~cm}^{-1}$ does not change in intensity but decreases in linewidth upon ion pair formation.

We obtain a more quantitative insight from a global fit including the effective ion pair extinctions for $\mathrm{HCl}$ and $\mathrm{HBr}$ as well as the ion pair difference spectrum. The resulting fit parameters are given in Table 2 . In our fit, we assume that the
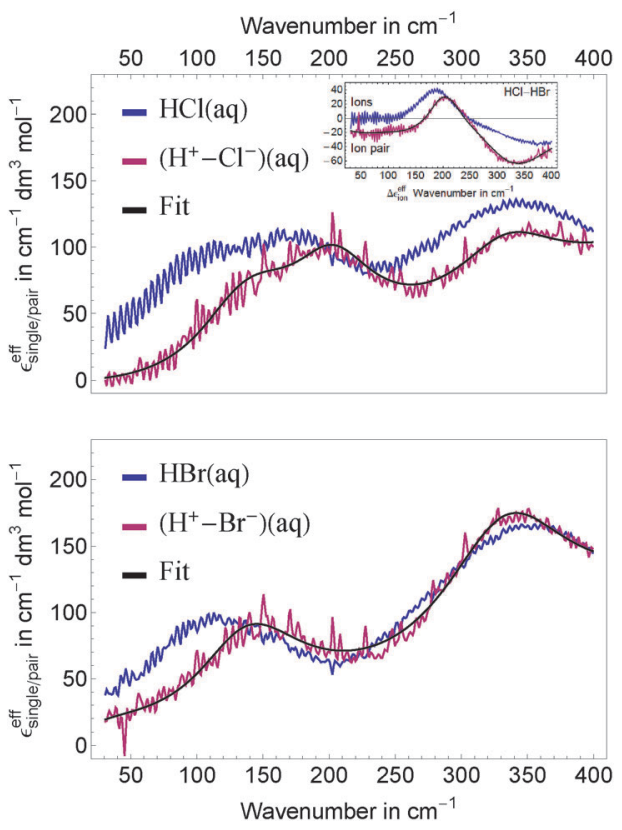

Fig. 6 Comparison of single ion and ion pair extinction spectra for $\mathrm{HCl}$ (top) and $\mathrm{HBr}$ (bottom). The inset in the top panel shows the extinction differences $\mathrm{HCl}-\mathrm{HBr}$ for single ions (in blue) and ion pairs (in red).

unperturbed center fequencies of the water mode at $140 \mathrm{~cm}^{-1}$ and of the solvated proton mode at $336 \mathrm{~cm}^{-1}$ are ion pair independent. However, we cannot exclude a different coupling to thermal bath states available in the solution, which yields differences in observed linewidths and apparent center frequencies $\tilde{\nu}_{\mathrm{d}}$. In the difference spectrum $\varepsilon_{\text {pair }}^{\text {eff }}\left(\mathrm{H}^{+}-\mathrm{Cl}^{-}\right)-\varepsilon_{\text {pair }}^{\text {eff }}$ $\left(\mathrm{H}^{+}-\mathrm{Br}^{-}\right.$) (see inset in Fig. 6) we find no indication of a $\mathrm{Br}^{-}$rattling signature. Compared to $\varepsilon_{\text {single }}^{\text {eff }}$ of the single ions, the ion pairs show a reduced influence on the hydration water. Our model is consistent with the assumption of vanishing $n_{\text {hydration }}$ for $\left(\mathrm{H}^{+}-\mathrm{Cl}^{-}\right)$and $\left(\mathrm{H}^{+}-\mathrm{Br}^{-}\right)$ion pairs: an attempt to include $n_{\text {hydration }}$ for the two ion pairs in the fit yielded a value of zero within our measurement uncertainties. Thus, in order to minimize the number of fit parameters, we set $n_{\text {hydration }}=0$ in the final fit.

The influence of the ion pairs on the librational band (as characterized by $n_{\mathrm{HF}}$ ) is strongly reduced for $\left(\mathrm{H}^{+}-\mathrm{Cl}^{-}\right)$and $\left(\mathrm{H}^{+}-\mathrm{Br}^{-}\right)$compared to the single ion spectra. Concerning the broad band low frequency relaxational component described by $n_{\mathrm{LF}}$, there is a distinct difference between $\mathrm{HCl}$ and $\mathrm{HBr}: n_{\mathrm{LF}}$ vanishes for $\left(\mathrm{H}^{+}-\mathrm{Cl}^{-}\right)$. For $\left(\mathrm{H}^{+}-\mathrm{Br}^{-}\right)$the broadband continuum is still observed but reduced by a factor of two compared to the free ions. The linewidth of the resonance attributed to $\mathrm{Cl}^{-}$in the solvated ion pair complex is only slightly increased upon ion pair formation. In contrast, the linewidths of the water and $\mathrm{H}_{3} \mathrm{O}^{+}$resonances obtained from the ion pair extinction spectra are significantly smaller than those obtained for the single ions (see Tables 1 and 2). We propose that this is an indication for the reduced average mobility in the librational motion of the solvent molecules in the high concentration limit compared to dilute solutions. $^{32}$ 
Table 2 Center frequency $\tilde{\nu}_{\mathrm{d}}$, corrected center frequency $\tilde{\nu}_{0}$, amplitude $a$, and linewidth $w$ for ion pairs of solvated $\mathrm{H}^{+}$and $\mathrm{X}^{-}(\mathrm{X}=\mathrm{Cl}, \mathrm{Br})$. obtained from a global fit of both ion pair extinctions and their anionic difference spectrum. We have used the same notification as in Table 1

\begin{tabular}{|c|c|c|c|}
\hline Assignment & Parameter & $\mathrm{H}^{+}-\mathrm{Cl}^{-}(\mathrm{aq})$ & $\mathrm{H}^{+}-\mathrm{Br}^{-}(\mathrm{aq})$ \\
\hline Water libration & $n_{\mathrm{HF}}$ & $2.8(1)$ & $\mathrm{HCl}$ \\
\hline $\mathrm{H}^{+}(\mathrm{aq})$ & $\begin{array}{l}\tilde{\nu}_{\mathrm{d}} \text { in } \mathrm{cm}^{-1} \\
\tilde{\nu}_{0} \text { in } \mathrm{cm}^{-1} \\
a \text { in } \mathrm{cm}^{-1} \mathrm{dm}^{3} \mathrm{~mol}^{-1} \\
w \text { in } \mathrm{cm}^{-1} \\
\tau \text { in fs }\end{array}$ & $\begin{array}{l}331(1) \\
336(2) \\
593(22) \\
\text { wlfm }\left(\mathrm{H}^{+}-\mathrm{Cl}^{-}\right) \\
\text {wlfm }\left(\mathrm{H}^{+}-\mathrm{Cl}^{-}\right)\end{array}$ & $\begin{array}{l}328(1) \\
\mathrm{HCl} \\
1307(21) \\
384(6) \\
86\end{array}$ \\
\hline
\end{tabular}

The deduced ion pair data are consistent with a model, where the band centers of the solvated $\mathrm{H}_{3} \mathrm{O}^{+}$mode at $336 \mathrm{~cm}^{-1}$ and the low frequency water mode at $143 \mathrm{~cm}^{-1}$ are unaltered upon ion pair formation. This favors the idea that solvent shared ion pairs are formed instead of contact ion pairs. Our interpretation is supported by the observation that in case of $\left(\mathrm{H}^{+}-\mathrm{Cl}^{-}\right)$the $\mathrm{Cl}^{-}$resonance shifts from 187 to $204 \mathrm{~cm}^{-1}$ which is considerably smaller than the shift from 187 to $240 \mathrm{~cm}^{-1}$ in case of $\left(\mathrm{Ni}^{2+}-\mathrm{Cl}^{-}\right)$and $\left(\mathrm{Mn}^{2+}-\mathrm{Cl}^{-}\right)$both of which form contact ion pairs. ${ }^{49}$

In addition, recent theoretical work ${ }^{32,64}$ predicts solvent shared (separated by one solvation layer) and solvent separated (two layers) ion pairs for the concentration range (0.05-3.2 M) covered in this work. DFT simulations by Heuft and Meijer ${ }^{31}$ for the concentration range 2.7-5.3 $\mathrm{M}$ show a change from $\left(\mathrm{Cl}^{-}-\mathrm{Cl}^{-}\right)$and $\left(\mathrm{H}_{3} \mathrm{O}^{+}-\mathrm{Cl}^{-}\right)$'pairs' bridged by two and more water at low concentrations to pairs bridged by a single water molecule for the higher concentration. Upon solvent separated ion pair formation in both cases (anion-anion, anion-cation) the $\mathrm{Cl}^{-}-\mathrm{H}_{\mathrm{H}_{2} \mathrm{O}}$ distance is found to be reduced from 2.3 to about $2.15 \AA$ An increased confinement is in agreement with the observation of a blue-shift of the $\mathrm{Cl}^{-}$band for the ion pair.

\section{Summary and conclusion}

Using principal component analysis of concentration dependent THz/FTIR measurements of $\mathrm{HCl}, \mathrm{HBr}$, and $\mathrm{DCl}$, we were able to extract single ion and ion pair extinction spectra. We find distinct resonances in the frequency range $30-400 \mathrm{~cm}^{-1}$. The band centers of these resonances provide information on the local structure of the hydration environment while the linewidths allow a glimpse on the fs-dynamics of the hydrogen bond network.
The acidic single ion extinction spectra were compared to our previous results on solvated transition metals. ${ }^{49}$ We find that the local solvation environment for $\mathrm{Cl}^{-}$is only slightly changed when we replace transition metal cations by the solvated proton as counter cation (see Table 1, Fig. 4 and Table 1 in Sharma et $a l .{ }^{49}$ ). In contrast, for the acidic solution we were unable to observe the weak $\mathrm{Br}^{-}$resonance within our experimental uncertainty. This is attributed to the faster H-bond relaxation dynamics $(\tau \approx 60 \mathrm{fs})$ in acidic solutions compared to those of salty electrolytes $(\tau \approx 70-120 \mathrm{fs})$.

The addition of $\mathrm{HCl}$ and $\mathrm{HBr}$ has only minor effects on the water translational and librational modes as can be seen by the small numbers for $n_{\text {hydration }}$ and $n_{\text {lib }}$ in Table 1 . We speculate that for both acids $n_{\text {hydration }}$ and $n_{\text {lib }}$ are dominated by contributions from anionic hydration shells. Based on this assumption we obtain solvation shell sizes of 5-7 for $\mathrm{Cl}^{-}$, $\mathrm{Br}^{-}, \mathrm{Ni}^{2+}$, and $\mathrm{Mn}^{2+}$ which are in good agreement with previous experimental and theoretical data. ${ }^{31,59}$

The dissection of the concentration dependent measurements yields three components describing the effect of the solvated proton: a high frequency cationic band at $340 \mathrm{~cm}^{-1}$, a low frequency hydration water band centered at $140 \mathrm{~cm}^{-1}$, and a broad background. The band at $340 \mathrm{~cm}^{-1}$ is assigned to a rattling mode of the solvated Eigen complex. This is in qualitative agreement with theoretical predictions. ${ }^{29,37}$ The assignment was confirmed by observation of a small redshift upon deuteration and is in agreement with a recent photoelectron study by Winter et al. ${ }^{18}$ and a combined NMR and ab initio study by ${ }^{23}$ who found $\mathrm{H}_{3} \mathrm{O}^{+}$as most likely structure in aqueous HCl mixtures.

The water resonance at $140 \mathrm{~cm}^{-1}$ shows a linewidth that is identical to that of the cationic mode at $340 \mathrm{~cm}^{-1}$. This is in contrast to hydrated $\mathrm{Ni}^{2+}$ and $\mathrm{Mn}^{2+}$ cations where the water mode shows significantly larger linewidth compared to the 


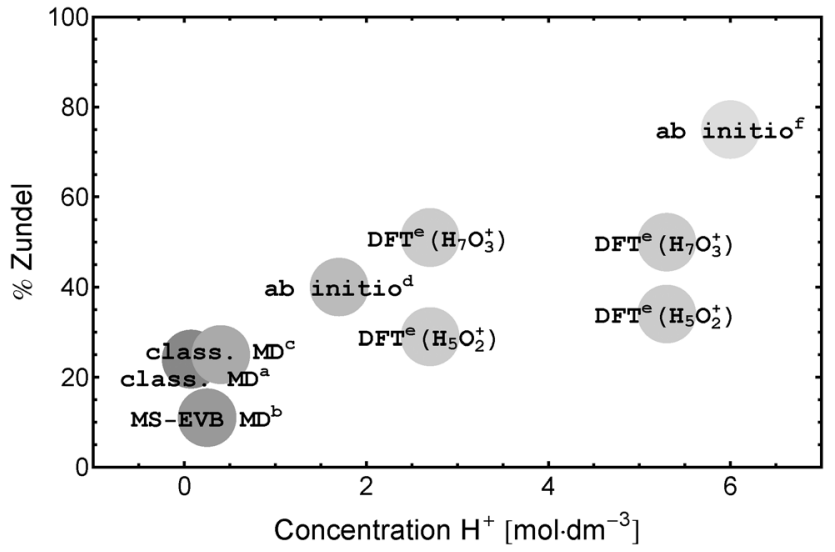

Fig. 7 Percentage of protons in the Zundel structure as predicted from theory: ${ }^{a}$ Wolf et al., ${ }^{28}{ }^{b}$ Markovitch et al., ${ }^{41}{ }^{c}$ Lapid et al., ${ }^{29}{ }^{d}$ Tuckerman et al., ${ }^{14}$ e Heuft and Meijer, ${ }^{31}{ }^{\text {Botti et al. }}{ }^{17}$

cationic resonances. We propose that this is an indication of rapid charge delocalization in an $\mathrm{H}_{9} \mathrm{O}_{4}{ }^{+}$Eigen complex ('special pair dance ${ }^{, 28,53}$ ) that makes a distinction between first and second solvation shell difficult.

The broad background is taken as evidence for fast nonoscillatory proton-dynamics in a Zundel-type solvation structure as expected in proton transport via an Eigen-Zundel-Eigen (EZE) mechanism. ${ }^{53,65}$ A comparison of the single ion and ion pair spectra (see Fig. 6) shows that this background is strongly reduced with increasing electrolyte concentration. Since, in contrast to ion mobility measurements, THz/FIR spectroscopy probes sub-ps processes this reduction is in line with a lower number of (fast) proton hops per ps compared to bulk water as predicted by DFT simulations. ${ }^{31}$ The combination of a quenched Zundel background and a persistent Eigen resonance on ion pairing puts severe limitations on simulations and experiments that predict an increase of the probability to find a Zundel structure with increasing proton concentration (see Fig. 7). This result is at variance with infrared data that claim dominant Zundel structures ${ }^{26}$ or a well defined hexacoordinated proton-water complex with a Zundel core. ${ }^{6,39}$

Upon ion pairing, we observe a blueshift of the $\mathrm{Cl}^{-}$resonance by about $20 \mathrm{~cm}^{-1}$. Based on a comparison to the more strongly shifted peaks observed in transition metal contact ion pairs $\left(\approx 40 \mathrm{~cm}^{-1}\right)$ we take this as evidence for solvent shared ion pairs in the concentration range up to $3.2 \mathrm{M}$ investigated by us. This is in agreement with theoretical predictions. ${ }^{31,32}$ For the solvated proton $\mathrm{H}_{\text {pair }}{ }^{+}$and its interaction with hydration water, our data are consistent with a model where the unperturbed center frequencies $\tilde{\nu}_{0}$ (see Tables 1 and 2) of the damped harmonic oscillator resonances remain unchanged while the linewidths decrease. We conclude that the local structure is still intact while the distribution of the thermal bath states is assumed to be affectd leading to increased relaxation times $\tau$.

Our measurements demonstrate that by a rigorous analysis of low frequency intermolecular modes THz/FTIR spectroscopy is able to shed light onto strongly debated solvation processes. In the case of the solvated proton we find experimental evidence that both, Eigen and Zundel species are present in acidic solutions: the solvated Eigen structure shows a prominent cationic peak with a decay time of 60 fs while the highly dynamic Zundel structure with correlation times below 10 fs is present as broad background.

\section{Acknowledgements}

We acknowledge $\mathrm{H}$. Weingärtner for helpful discussions and Gudrun Niehues and Stefan Funkner for accurate measurements of the low frequency spectrum of $\mathrm{D}_{2} \mathrm{O}$. This work is supported by the Cluster of Excellence RESOLV (EXC1069) funded by the Deutsche Forschungsgemeinschaft.

\section{References}

1 M. Eigen, Angew. Chem., Int. Ed. Engl., 1964, 3, 1-19.

2 D. Marx, ChemPhysChem, 2006, 7, 1848-1870.

3 B. Kirchner, ChemPhysChem, 2007, 8, 41-43.

4 D. Marx, A. Chandra and M. E. Tuckerman, Chem. Rev., 2010, 110, 2174-2216.

5 C. Knight and G. A. Voth, Acc. Chem. Res., 2012, 45, 101-109. 6 C. A. Reed, Acc. Chem. Res., 2013, 46, 2567-2575.

7 A. A. Hassanali, J. Cuny, V. Verdolino and M. Parrinello, Philos. Trans. R. Soc., A, 2014, 372, 20120482.

8 C. J. T. Grotthus, Ann. Chim. (Cachan, Fr.), 1806, 58, 54-73.

9 E. G. Weidemann, Z. Phys., 1967, 198, 288-303.

10 G. Zundel and H. Metzger, Z. Phys. Chem., 1968, 58, 225-245.

11 J. D. Bernal and R. H. Fowler, J. Chem. Phys., 1933, 1, 515.

12 R. P. Bell, Proc. R. Soc. London, 1936, 154, 414-429.

13 A. J. Huneycutt and R. J. Saykally, Science, 2003, 299, 1329-1330.

14 M. Tuckerman, K. Laasonen, M. Sprik and M. Parrinello, J. Phys. Chem., 1995, 99, 5749-5752.

15 D. Marx, M. E. Tuckerman, J. Hutter and M. Parrinello, Nature, 1999, 397, 601-604.

16 D. Asthagiri, L. R. Pratt and J. D. Kress, Proc. Natl. Acad. Sci. U. S. A., 2005, 102, 6704-6708.

17 A. Botti, F. Bruni, M. A. Ricci and A. K. Soper, J. Chem. Phys., 2006, 125, 014508.

18 B. Winter, M. Faubel, I. V. Hertel, C. Pettenkofer, S. E. Bradforth, B. Jagoda-Cwiklik, L. Cwiklik and P. Jungwirth, J. Am. Chem. Soc., 2006, 128, 3864-3865.

19 A. Hassanali, F. Giberti, J. Cuny, T. D. Kühne and M. Parrinello, Proc. Natl. Acad. Sci. U. S. A., 2013, 110, 13723-13728.

20 J. M. Headrick, E. G. Diken, R. S. Walters, N. I. Hammer, R. A. Christie, J. Cui, E. M. Myshakin, M. A. Duncan, M. A. Johnson and K. D. Jordan, Science, 2005, 308, 1765-1769.

21 J. A. Fournier, C. J. Johnson, C. T. Wolke, G. H. Weddle, A. B. Wolk and M. A. Johnson, Science, 2014, 344, 1009-1012. 22 R. Triolo and A. H. Narten, J. Chem. Phys., 1975, 63, 3624.

23 T. Murakhtina, J. Heuft, E. J. Meijer and D. Sebastiani, ChemPhysChem, 2006, 7, 2578-2584. 
24 S. Woutersen and H. J. Bakker, Phys. Rev. Lett., 2006, 96, 138305. 25 M. Śmiechowski and J. Stangret, J. Chem. Phys., 2006, 125, 204508.

26 M. Śmiechowski and J. Stangret, J. Mol. Struct., 2008, 878, 104-115.

27 W. Kulig and N. Agmon, Nat. Chem., 2013, 5, 29-35.

28 M. G. Wolf and G. Groenhof, J. Comput. Chem., 2014, 35, 657-671.

29 H. Lapid, N. Agmon, M. K. Petersen and G. A. Voth, J. Chem. Phys., 2005, 122, 14506.

30 K. E. Laasonen and M. L. Klein, J. Phys. Chem. A, 1997, 101, 98-102.

31 J. M. Heuft and E. J. Meijer, Phys. Chem. Chem. Phys., 2006, 8, 3116-3123.

32 J. Xu, S. Izvekov and G. A. Voth, J. Phys. Chem. B, 2010, 114, 9555-9562.

33 M. Miyazaki, A. Fujii, T. Ebata and N. Mikami, Science, 2004, 304, 1134-1137.

34 J.-W. Shin, N. Hammer, E. Diken, M. Johnson, R. Walters, T. Jaeger, M. Duncan, R. Christie and K. Jordan, Science, 2004, 304, 1137-1140.

35 S. Olesen, T. Guasco, J. Roscioli and M. Johnson, Chem. Phys. Lett., 2011, 509, 89-95.

36 A. Botti, F. Bruni, S. Imberti, M. A. Ricci and A. K. Soper, J. Chem. Phys., 2004, 120, 10154-10162.

37 J. Kim, U. W. Schmitt, J. A. Gruetzmacher, G. A. Voth and N. E. Scherer, J. Chem. Phys., 2002, 116, 737.

38 J. L. Fulton and M. Balasubramanian, J. Am. Chem. Soc., 2010, 132, 12597-12604.

39 E. S. Stoyanov, I. V. Stoyanova and C. A. Reed, Chem. Sci., 2011, 2, 462-472.

40 C. Chen, C. Huang, I. Waluyo, D. Nordlund, T.-C. Weng, D. Sokaras, T. Weiss, U. Bergmann, L. G. Pettersson and A. Nilsson, J. Chem. Phys., 2013, 138, 154506.

41 O. Markovitch and N. Agmon, J. Phys. Chem. A, 2007, 111, 2253-2256.

42 W. Amir, G. Gallot, F. Hache, S. Bratos, J.-C. Leicknam and R. Vuilleumier, J. Chem. Phys., 2007, 126, 034511.

43 K. J. Tielrooij, R. L. A. Timmer, H. J. Bakker and M. Bonn, Phys. Rev. Lett., 2009, 102, 198303.

44 S. Ebbinghaus, S. J. Kim, M. Heyden, X. Yu, U. Heugen, M. Gruebele, D. M. Leitner and M. Havenith, Proc. Natl. Acad. Sci. U. S. A., 2007, 104, 20749-20752.
45 J. Sun, G. Niehues, H. Forbert, D. Decka, G. Schwaab, D. Marx and M. Havenith, J. Am. Chem. Soc., 2014, 136, 5031-5038.

46 D. A. Schmidt, S. Funkner, B. P. Born, R. Gnanasekaran, G. W. Schwaab, D. M. Leitner and M. Havenith, J. Am. Chem. Soc., 2009, 131, 18512-18517.

47 S. Funkner, G. Niehues, D. A. Schmidt, M. Heyden, G. Schwaab, K. M. Callahan, D. J. Tobias and M. Havenith, J. Am. Chem. Soc., 2012, 134, 1030-1035.

48 V. Sharma, F. Böhm, M. Seitz, G. Schwaab and M. Havenith, Phys. Chem. Chem. Phys., 2013, 15, 8383-8391.

49 V. Sharma, F. Böhm, G. Schwaab and M. Havenith, Phys. Chem. Chem. Phys., 2014, 16, 25101-25110.

50 O. Redlich and J. Bigeleisen, J. Am. Chem. Soc., 1941, 64, 1941-1943.

51 F. J. Millero, Water and Aqueous Solutions, Wiley, New York, 1972.

52 K. S. Pitzer and G. Mayorga, J. Phys. Chem., 1973, 77, 2300-2308.

53 O. Markovitch, H. Chen, S. Izvekov, F. Paesani, G. A. Voth and N. Agmon, J. Phys. Chem. B, 2008, 112, 9456-9466.

54 A. Chandra, M. E. Tuckerman and D. Marx, Phys. Rev. Lett., 2007, 99, 145901.

55 M. E. Tuckerman, A. Chandra and D. Marx, J. Chem. Phys., 2010, 133, 124108.

56 M. D. Fayer, Acc. Chem. Res., 2012, 45, 3-14.

57 M. Heyden, J. Sun, S. Funkner, G. Mathias, H. Forbert, M. Havenith and D. Marx, Proc. Natl. Acad. Sci. U. S. A., 2010, 107, 12068-12073.

58 H. Ohtaki and T. Radnai, Chem. Rev., 1993, 93, 1157-1204.

59 Y. Marcus, Chem. Rev., 2009, 109, 1346-1370.

60 M. Trumm, Y. O. G. Martńez, F. Réal, M. Masella, V. Vallet and B. Schimmelpfennig, J. Chem. Phys., 2012, 136, 044509.

61 V. Migliorati, F. Sessa, G. Aquilanti and P. D'Angelo, J. Chem. Phys., 2014, 141, 044509.

62 T. C. Berkelbach, H.-S. Lee and M. E. Tuckerman, Phys. Rev. Lett., 2009, 103, 238302.

63 C. Rønne, P.-O. Åstrand and S. R. Keiding, Phys. Rev. Lett., 1999, 82, 2888.

64 F. Wang, S. Izvekov and G. A. Voth, J. Am. Chem. Soc., 2008, 130, 3120-3126.

65 N. Agmon, Chem. Phys. Lett., 1995, 244, 456-462. 